\title{
The Changing Landscapes in DCD Liver Transplantation
}

\author{
Kristopher P. Croome ${ }^{1} \cdot$ C. Burcin Taner ${ }^{1}$
}

Published online: 13 July 2020

(C) Springer Nature Switzerland AG 2020

\begin{abstract}
Purpose of Review The transplant community continues to look for ways to help address the discordance between donor liver graft availability and patients on the liver transplant waiting list. Donation after circulatory death (DCD) donor livers represents one potential means to help address this discordance. The present review describes the changing landscape of DCD liver transplantation (LT).

Recent Findings The number of DCD LTs performed annually within the USA has continued to grow on an annual basis. Importantly, national data has demonstrated that outcomes with DCD LT have been improving. This improvement has been driven by better understanding of how to successfully utilize these organs through better donor and recipient matching and careful evaluation of both hemodynamics during withdrawal of life support and the refinement of the procurement operation.

Summary Despite these improvements in outcome, ischemic cholangiopathy (IC) continues to be the Achilles heel of DCD LT. Emerging technologies such as various forms of machine perfusion may allow for reduction of complications and better prognostication of the risk associated with DCD liver grafts.
\end{abstract}

Keywords DCD $\cdot$ Non-heart beating $\cdot$ Ischemic cholangiopathy $\cdot$ Allocation

$\begin{array}{ll}\text { Abbreviations } \\ \text { AKI } & \text { Acute kidney injury } \\ \text { CIT } & \text { Cold ischemia time } \\ \text { DCD } & \text { Donation after circulatory death } \\ \text { DBD } & \text { Donation after brain death } \\ \text { DRI } & \text { Donor risk index } \\ \text { DWIT } & \text { Donor warm ischemia time } \\ \text { EAD } & \text { Early allograft dysfunction } \\ \text { fDWIT } & \text { Functional donor warm ischemia time } \\ \text { HCC } & \text { Hepatocellular carcinoma } \\ \text { HMP } & \text { Hypothermic machine perfusion } \\ \text { IC } & \text { Ischemic cholangiopathy } \\ \text { LT } & \text { Liver transplant } \\ \text { MELD } & \text { Model for end-stage liver disease } \\ \text { NMP } & \text { Normothermic ex vivo perfusion } \\ \text { NRP } & \text { Normothermic regional perfusion } \\ \text { PNF } & \text { Primary non-function }\end{array}$

This article is part of the Topical Collection on Liver Transplantation

Kristopher P. Croome

croome.kristopher@mayo.edu

1 Department of Transplant, Mayo Clinic Florida, 4500 San Pablo Road, Jacksonville, FL 32224, USA
PRS Post-reperfusion syndrome

SCS Static cold storage

SD Standard deviation

\section{Introduction}

The transplant community continues to look for ways to help address the discordance between donor liver graft availability and patients on the liver transplant waiting list. Donation after circulatory death (DCD) donor livers represents one potential means to help address this discordance. Initial reports examining the use of liver grafts from DCD described inferior longterm outcomes when compared with donation after brain death donors (DBD). These inferior results were ascribed to high rates of biliary complications, as well as increased rates of primary non-function and hepatic artery thrombosis [1-4]. Since those initial publications, there have been substantial developments in the understanding of how to effectively utilize DCD livers. More recent single center publications from high volume DCD programs have demonstrated equivalent outcomes between DCD and DBD liver transplantation (LT), with appropriate donor and recipient selection [5-7]. The present review describes the changing landscape of DCD LT. 


\section{Increased DCD LT Volumes}

Prior to the development of the Harvard criteria for brain death in 1968, all deceased organ donors were declared deceased using circulatory arrest criteria and thus represented the first DCD organ transplants performed [8]. Following the acceptance of declaration of death according to neurologic criteria as a legal entity, most countries including the USA almost exclusively utilized DBD donors until the 1990s. Resurgence of DCD LT was first described by groups from Pittsburgh and Wisconsin in the mid-1990s [9, 10]. Excitement surrounded DCD LT resulted in rapid growth in the number of transplants performed from 1994 until 2007 (Fig. 1). This initial excitement was tempered by multiple reports that described high rates of complications, specifically ischemic cholangiopathy (IC), resulting in graft failure or patient death following DCD LT [1-4]. These results led to a contraction in the number of DCD LTs performed from 2007 until 2012. As more data began to emerge demonstrating that acceptable results with DCD LT could be achieved with appropriate donor and recipient selection, the number of DCD LT performed annually has continued to grow from 2012 to 2018.

In addition to increasing DCD LT volumes, a concomitant improvement in US national results with DCD LT has taken place. We previously demonstrated a sequential improvement in both graft and patient survival from 2003 to 2014 following DCD LT [11 “* (Fig. 2). Moreover, changes in both recipient and donor characteristics consistent with published literature during the aforementioned time period were observed between eras. As with all innovations in transplant practice, there is undoubtedly a learning curve associated with the optimal

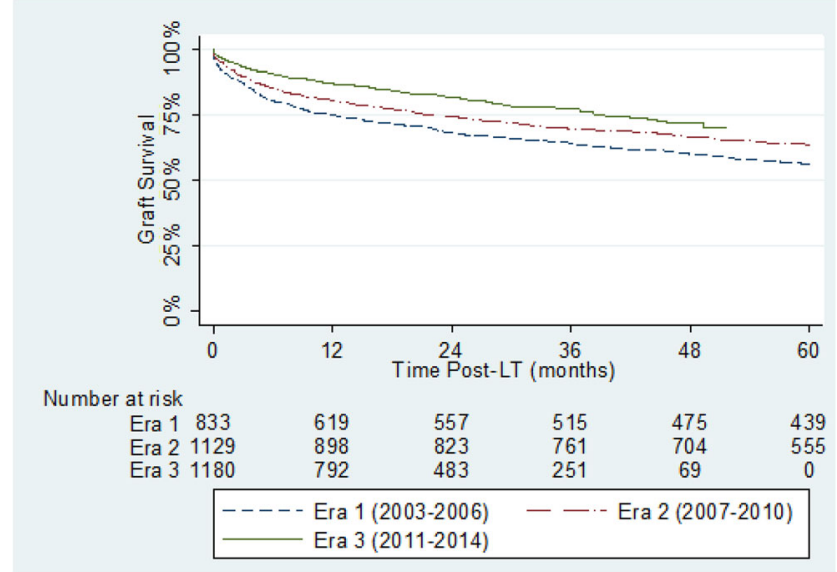

Fig. 2 Graft survival following DCD LT divided by era [5]. KaplanMeier graft survival estimates by era of DCD LT. Era 1 versus era 2 $(P=0.001)$, era 2 versus era $3(P<0.001)$, and era 1 versus era 3 $(P<0.001)$

utilization of liver grafts from DCD donors which has taken place as new data and analyses have become available. Changes that were observed over the eras included:

1. Decrease in proportion of DCD LT used for recipients:
(a) In ICU at time of LT
(b) On ventilator at time of LT
(c) Listed for Redo-LT
(d) Listed for PSC

2. Increase in proportion for recipients:

(a) Listed for HCC
Fig. 1 Number of DCD liver transplants performed in the USA 1993-2018

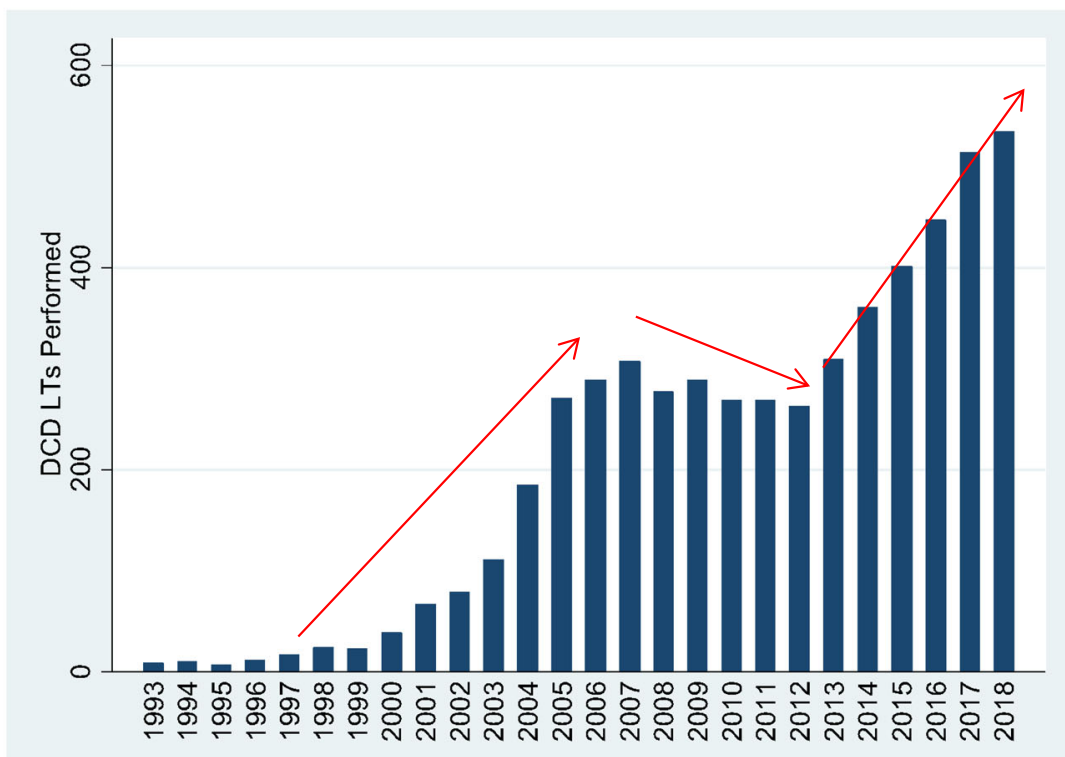


3. Decrease in donor warm ischemia time (DWIT)

4. Decrease in cold ischemia time (CIT)

\section{Changes to Allocation and Effects on DCD Liver Transplantation}

Donor liver allocation in the USA has never been more contentious. Following years of debate and legal challenges from all sides, a liver distribution system based on acuity circles went into effect on February 4, 2020 [12]. This acuity circle allocation system replaces donation service area (DSA) and regional boundaries previously used in liver organ distribution with a system based on distance between donor hospital and transplant hospital. This system will result in broader sharing of livers and substantially increase both the distances traveled and the costs for organ retrieval. It is also predicted that this system will reduce MELD score disparity across the USA.

In the newly adopted acuity system, livers from DCD donors are allocated earlier in the match sequence to transplant centers closer to the donor hospital compared with liver donor allocation for DBD donors $<70$ years of age (Fig. 3). For livers from DCD donors, after initial offers to status $1 \mathrm{~A}$ and $1 \mathrm{~B}$ candidates, the initial distribution sequence is as follows:

- compatible candidates with a MELD or PELD of 15 or higher, listed at transplant hospitals within a 150 nauticalmile radius of the donor hospital

- compatible candidates with a MELD or PELD of 15 or higher, listed at transplant hospitals within a 250 nauticalmile radius of the donor hospital

- compatible candidates with a MELD or PELD of 15 or higher, listed at transplant hospitals within a 500 nauticalmile radius of the donor hospital

The effects that allocation changes will have on DCD LTs remain unknown. Substantial variability in the

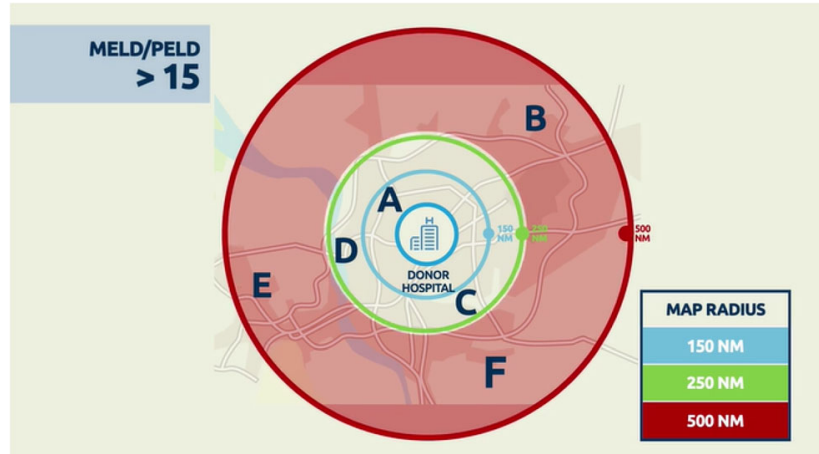

Fig. 3 New acuity circle organ distribution for DCD donors [12] utilization of DCD livers currently exists across the country $\left[13^{*}\right]$. This variability in DCD liver utilization has been shown to have no correlation with median MELD score at transplant $\left[13^{\circ}\right]$. Indeed, it is known that DCD utilization in the USA is driven by a few high-utilization centers [14]. Likely, the new allocation changes will result in significant changes to behavior both from transplant centers as well as OPOs with regard to the pursuit and utilization of DCD livers. Transplant center behavior has previously been shown to account at least partially for significant variability in median MELD score at transplant both inter- and intra-regionally [15].

One question to be answered is whether transplant centers will be willing to travel substantial distances for DCD livers? A previous single-center study demonstrated that each successful DCD liver procurement required an average of 218 more miles of travel than each successful DBD liver procurement [16]. This difference was largely due to lower successful procurement proportion among DCD procurement episodes. Only $49.7 \%$ of DCD liver offers resulted in a liver procured for transplant, compared with $92.3 \%$ of DBD. As a result, the authors of this paper suggested that current reimbursement policies poorly reflect increased surgeon travel (and time) expenditures between DCD and DBD liver offers. While several tools exist in order to predict the likelihood that a DCD donor will expire within $60 \mathrm{~min}$, their predictive value is moderate at best, making the decisions on which DCD liver donors to pursue challenging [17-19].

Historically, LT candidates with HCC have experienced a substantial advantage in deceased donor liver allocation with lower waitlist mortality/dropout within 1 year of listing compared with those candidates without a HCC diagnosis [20]. In addition to the recent implementation of the acuity circles system, deliberate steps have been taken to adjust HCC exception scores so that these transplant candidates are no longer so heavily advantaged. HCC patients no longer have a "ladder" model of increasing exception scores over time and instead are given an exception score of median MELD at transplant minus 3 (MMaT-3) for a 250 mile radius surrounding the listing center. Undoubtedly this will result in decreased access to highquality DBD organs for patients with HCC. One potential option for this population may be increased utilization of DCD livers. This potential shift is congruent with the principle of using extended criteria organs in recipients with lower biological MELD scores, such as many HCC patients, because of the perception that these recipients are better able to tolerate an extended criteria organ [21]. A previous publication demonstrated that after the implementation of the Share 35 policy, more HCC patients have received livers from DCD donors [22], potentially as the result of the highest quality organs being preferentially utilized by higher MELD recipients with broader sharing. 


\section{WIT and the Importance of the Procurement Operation}

Initial studies investigating LT using liver grafts from DCD donors linked prolonged donor warm ischemia time (DWIT) to biliary complications and graft loss $[3,23,24]$. While there is a general consensus that prolonged DWIT negatively effects outcome, there exists significant disagreement on what length of DWIT is acceptable and even on how DWIT is defined.

As the collective experience with DCD LT increased, a concept of functional donor warm ischemic time (fDWIT) arose from the notion that individual events during DCD procurement, such as variations in hemodynamics, mandatory wait period, time from incision to cannulation of the aorta and cross-clamp, all of which are included in total DWIT, may have different impacts on the outcome of the liver graft $[25,26]$. Previous studies have defined the start of f-DWIT based on different hemodynamic parameters (such as drop in mean arterial pressure (MAP) or sBP) or by a drop in oxygen saturation below a specific level. F-DWIT terminates at the time of cold organ flush/cross-clamp. While the concept of $\mathrm{f}$ DWIT is ubiquitously accepted, no consensus on what parameters specifically define f-DWIT exists [27]. Previously published National and Society Guidelines for fDWIT can be seen in Table 1 [28-31]. Recently, a consensus conference on DCD LT transpired in Venice, Italy (January 30, 2020) in which attempts to more uniformly define and describe DWIT and fDWIT were made. The results of this consensus meeting have yet to be published.

The importance of the procurement operation in order to achieve successful outcomes with DCD LT should not be understated. Not only is it imperative to be able to quickly cannulate the donor vessels and begin cold perfusion of the liver, but judgement as to the timing and length of fDWIT, flush quality, and overall liver appearance is paramount. Judgement comes with experience and many of the high-

Table 1 Published national and society guidelines for functional donor warm ischemia time (fDWIT)

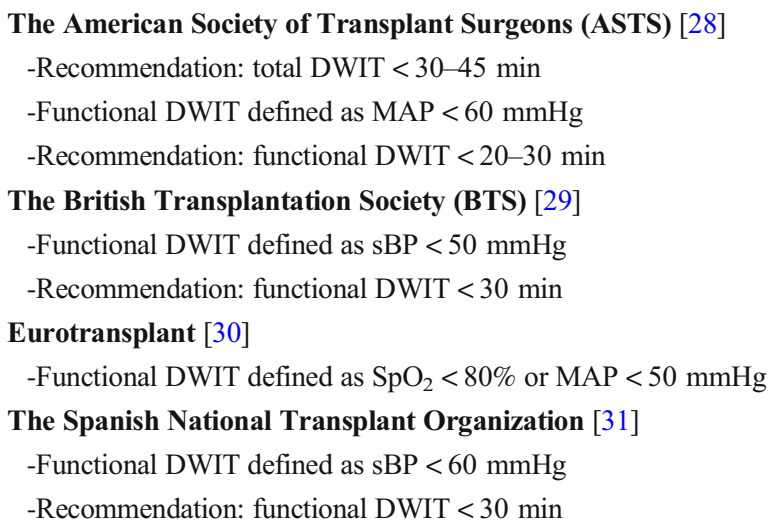

volume transplant centers will only utilize DCD livers in cases where the procurement has been performed by a member (frequently an attending surgeon) of their team. This judgement on whether the liver is "usable" even more heavily relies on procuring surgeon experience when attempting to utilize extended criteria (ECD) DCD liver grafts.

The fundamental techniques of the procurement operation have changed very little since the initial description of the "super rapid technique" [9]. Many components of DWIT are not modifiable since they occur prior to final pronouncement of donor death. Alternatively, the time from final pronouncement of death until cold flush of the organs is largely within the procuring surgeon's control. The procuring surgeon should discuss the steps of the procedure with all assistants and operating room personnel prior to withdrawal of care. Once the "no touch" time has transpired and the donor is declared deceased, efforts to cannulate and began cold flush in under 2 min should be made.

Donor hepatectomy time is the time from initiation of cold perfusion to the end of the hepatectomy and removal of the liver from the donor. As a general rule, extraction of the liver from the body of a DCD donor should be done as quickly and safely as possible. Several recent reports have suggested that donor hepatectomy time (DHT) may be associated with outcomes following DCD LT $[32,33]$. In a study from the UK, DHT $>60 \mathrm{~min}$ was associated with primary non-function (PNF) [32]. An abstract from the Netherlands demonstrated that DHT > 90 min was associated with both IC and early graft loss [34].Whether prolonged DHT is itself a risk factor, or simply a proxy for donor surgeon inexperience, is unknown. It has previously been demonstrated that transplant center standardization of organ acceptance criteria (such as donor BMI, donor age, CIT, DWIT), procurement operation (such as acceptable f-DWIT, asystole-to-cross-clamp time), and experienced procurement team help decrease complication rates related to DCD LT [26].

\section{Recipient Selection and Importance of Donor and Recipient Matching}

Recipient selection is equally if not more important than donor selection in order to achieve optimal outcomes with DCD LT. Previously published registry studies (both SRTR and UK national registry) have demonstrated that the following recipient characteristics are associated with increased hazard of graft loss following DCD LT: recipient in the ICU, recipient on ventilator, elevated MELD score, advanced recipient age, recipient undergoing retransplantation $[24,35,36 \bullet \bullet$. DCD liver grafts have by definition already undergone an ischemic insult through mandatory warm ischemia in the period between withdrawal of life support and cold perfusion in the donor. As such, the goal of the recipient implantation 
procedure should be to minimize surgical complexity and recipient instability as much as possible to avoid a tenuous environment for an already marginal graft. In an effort to more objectively define recipient surgical complexity when using marginal grafts, the group from Ochsner Clinic developed an "ABC" surgical risk score [37]. For this score, liver transplant candidates are assigned a surgical risk score of A (low), B (moderate), and C (high) at the time of pre-transplant surgical evaluation with re-review at the time of presentation of the patient to the transplant selection committee. At the time of organ offer, marginal liver grafts (including DCDs) are primary utilized for A-B candidates with general avoidance of C candidates. At Mayo Clinic Florida, we utilize a similar surgical complexity scoring system based on a 1-5-point scale and do not even list patients with a surgical score of 5 for DCD organs (Tables 2 and 3 ).

In selecting an appropriate recipient for a DCD liver graft, it is also important to choose a recipient that can tolerate early allograft dysfunction (EAD). Previous studies have demonstrated that EAD has been shown to have a baseline rate of 23-27\% in generalized cohorts of patients undergoing LT [38, 39]. With DCD LT, the rate of EAD is significantly higher (34-40\%) [40, 41]. Recipients who have high MELD scores and are in the ICU, recipients with a significant cardiac history, or recipients with compromised renal function may not be ideal candidates since they may not be able to tolerate EAD. Some of the general principles to follow when selecting an appropriate DCD LT recipient can be seen in below:

1. Minimize surgical complexity by avoiding:

(b) Difficult hepatectomy (redo, prev. Liver resection)

(c) Complex vascular reconstruction

(d) Prolonged CIT

2. Minimize tenuous environment for marginal graft by avoiding:

(a) High vasopressor requirements

Table 2 The Ochsner-ABC system

\begin{tabular}{|c|c|}
\hline & Surgical complexity \\
\hline Group A low & $\begin{array}{l}\text { LT alone, absence-moderate obesity; patent } \\
\text { portal vein (PV), no upper abdomen } \\
\text { surgeries (except lap cholecystectomy). }\end{array}$ \\
\hline Group B moderate & $\begin{array}{l}\text { Combined LKT, moderate-severe obesity, } \\
\text { history of spontaneous bacterial } \\
\text { peritonistis (SBP), previous upper } \\
\text { abdomen operations, PV thrombosis }\end{array}$ \\
\hline Group C high & $\begin{array}{l}\text { Re-transplantation, previous hepatobiliary or } \\
\text { foregut surgery, PV cavernous } \\
\text { transformation. }\end{array}$ \\
\hline
\end{tabular}

Table 3 The Mayo Surgical Risk Scores

\begin{tabular}{lc}
\hline Surgical score & Surgical complexity \\
\hline 1 & No history of surgery, lower abdominal surgery \\
& only (C-section/hysterectomy/appendectomy); \\
& lap cholecystectomy only; patent portal vein \\
& Partial non-occlusive PVT; significant SBP; \\
& Caudate that wraps cava without additional \\
& surgery; really obese patient \\
& Cholangiocarcinoma without significant previous \\
& surgery and no need for Whipple; straight \\
& forward polycystic liver; significant \\
& pancreatitis; occlusive PVT \\
& Previous major liver resection; significant upper \\
& abdominal surgery (open right nephrectomy; \\
& open gastric bypass; Whipple); more difficult \\
& polycystic liver \\
& Redo OLT; likely portal vein jump graft; \\
& cholangiocarcinoma with possible Whipple; \\
& cholangiocarcinoma with previous Whipple; \\
previous Kasai procedure
\end{tabular}

(b) Massive transfusion

(c) Poor oxygenation (hepatopulmonary syndrome)

3. Recipient that can tolerate early allograft dysfunction by avoiding:

(a) Patient intubated in the ICU

(b) Major cardiac issues

4. Access to biliary tree post-LT by avoiding:

\section{(a) Roux-en-Y?}

The appropriateness of utilizing DCD grafts for simultaneous liver kidney (SLK) recipients has previously been debated. Initial studies investigating the outcomes of simultaneous liver kidney (SLK) transplant using grafts from DCD donors described inferior outcomes compared with those using grafts from DBD donors (DBD-SLK) [42-44]. These studies demonstrated inferior patient survival as well as inferior liver and kidney graft survival with DCD-SLK compared with DBD-SLK transplant. More recently, a study investigating SRTR data demonstrated that there has been a significant improvement in the results with DCD SLKs in the modern era [45]. In that study, patients undergoing DCD SLK in the Era 2011-2018 were able to achieve similar outcomes compared with matched patients undergoing DBD-SLK transplant, with no differences seen in patient, liver graft, or kidney graft survival. It should be noted that donors used for DCD-SLK were generally younger with relatively shorter DWIT. In addition, a concomitant decrease in the proportion of patients in the ICU prior 
to DCD-SLK transplant was observed. It therefore seems that in select patients (not in the ICU prior to transplant) requiring an SLK, it may be appropriate to receive organs from younger DCD donors.

Another question that has frequently been raised is the appropriateness of DCD grafts for patients listed with HCC. With the changes to exception points for patients with HCC (MMaT-3 with no escalading ladder), it may become increasingly difficult to transplant patients with HCC with standard liver grafts. As such, patients with HCC, who generally have preserved liver function, may represent ideal candidates for DCD grafts. It has previously been postulated that the rate of HCC recurrence could be elevated in patients receiving a DCD allograft [46]. This postulate was based on biologic plausibility rather than direct evidence, as non-transplant studies have suggested that ischemia reperfusion injury is associated with stimulation of growth in micromestastases and in increasing the adhesion of tumor cells $[47,48]$. Despite the biologically plausible mechanism, a large single-center study demonstrated no difference in the rate of recurrence of HCC between DCD and DBD LT (12.3\% and 12.1\% respectively) [49]. More importantly, if ischemia reperfusion injury in the DCD grafts was felt to be an important factor in recurrence, one would expect to see a higher proportion of initial site of recurrence to be the liver in the DCD LT recipients. In fact, in that study, the opposite was true as the liver graft represented the first site of recurrence in $65 \%$ of recipients in the DBD group and only $37 \%$ of recipients in the DCD group.

Specific donor-and-recipient risk factors have been demonstrated to significantly affect outcomes following DCD LT. As such, several donor and recipient risk matching scores have been developed. These risk scores may be particularly useful for centers that are in the process of expanding their utilization of DCD liver grafts. Three different donor-recipient risk scores have been described $[36,50,51]$ :

\section{- UCLA-DCD Score \\ - DCD-Risk Index \\ - UK DCD-Risk Index}

The most recent of these scores, based on a large cohort of DCD LTs, is the UK DCD-Risk Index (Fig. 4) [36"“]. This score is based on 2 donor (donor age, donor BMI), 2 ischemic time (fDWIT and CIT), and 3 recipient (recipient age, recipient MELD, and re-transplantation status) variables. With these variables, a score between 0 and 27 is generated. DCD LTs in the low-risk group (score $\leq 5$ ) had a 1-year graft survival rate of $>95 \%$, compared with $>85 \%$ in the moderate risk group (score $6-10$ ) and $<40 \%$ in the futile group (score $>10$ ). The authors advocate avoidance of DCD LTs for the futile group.

\section{Utilization of ECD DCDs}

As the collective experience with DCD LTs has increased, several high-volume DCD centers have pursued ECD DCD LTs with acceptable results. Pursuit of these organs should be undertaken cautiously for centers with less experience with DCD LT or with less experience in the utilization of marginal grafts; however, in highly selected cases in experienced centers, they can be utilized with acceptable outcomes. Recent publications have described the utilization of two categories of ECD DCD LTs, namely elderly DCDs and steatotic DCDs.

As the population in the USA continues to age, there will undoubtedly be an increase in the number of potential donors with advanced chronological age. Multiple previous registry studies have demonstrated that advanced donor age DCDs have a higher risk of graft failure [24, 35, 36*0]. Therefore, there is little disagreement that younger is "better"; however, old is not necessarily "bad." Previously, a single-center study from the Birmingham, UK group investigated the outcomes of DCD donor age $>60$ years compared with those age $\leq 60$ years and demonstrated no differences in graft or patient survival between the groups [52]. In this study, the rate of vascular, biliary, and overall complications was similar between the groups. More recently, our group published a multicenter study that found there was no difference in graft survival between a DCD donor age $\geq 50$ group and a DCD donor age $<$ 50 group [53]. While the rate of IC was not statistically significant different between the groups, there was a slight trend of increased IC in the DCD donor age $\geq 50$ group (11.6\%) compared with the DCD donor age $<50$ group $(7.6 \%)$. In that study, using Cox regression analysis for national data, we evaluated predictors of graft failure in DCD donor age $\geq$ 50 years. Significant predictors of graft failure included a calculated MELD score $\geq 30$, mechanical ventilation at the time of transplant, medical condition (in ICU), and increasing CIT. As has been mentioned above in the previous section, when utilizing elderly DCD donors, appropriate recipient selection is paramount.

Given the potentially additive risk from using donor livers that are both steatotic and from a DCD donor, there is a paucity of data on the outcome of DCD LT utilizing livers with macrosteatosis [54]. In a recent multicenter analysis, we investigated the outcome of utilizing DCD liver grafts with macrosteatosis [55]. In that analysis, we found that DCD donors with macrosteatosis $<30 \%$ had no increase in peri-operative complications and similar patient and graft survival compared with DCD donors with no steatosis. In contrast, DCD liver grafts with moderate macrosteatosis $(30-60 \%)$ had higher rates of PRS, PNF, post-reperfusion cardiac arrest, EAD, and AKI compared with DCD donors with no steatosis. The data on the utilization of DCD liver grafts with steatosis remains limited; therefore, extreme caution should be taken when utilizing 


\begin{tabular}{l|l|l|}
\hline Parameter & Category & \\
\hline Donor Age & $\leq 60 \mathrm{yr}$ & 0 \\
\hline & $>60 \mathrm{yr}$ & 2 \\
\hline Donor BMI & $\leq 25 \mathrm{~kg} / \mathrm{m} 2$ & 0 \\
\hline & $>25 \mathrm{~kg} / \mathrm{m} 2$ & 3 \\
\hline Functional dWIT (sBP & $\leq 20 \mathrm{~min}$ & 0 \\
\hline$<50 \mathrm{mmHG}$ ) & $>20$ to $\leq 30 \mathrm{~min}$ & 3 \\
\hline & $>30 \mathrm{~min}$ & 6 \\
\hline CIT & $\leq 6 \mathrm{~h}$ & 0 \\
\hline Recipient Age & $>6 \mathrm{~h}$ & 2 \\
\hline Recipient lab MELD & $\leq 60 \mathrm{yr}$ & 0 \\
\hline Retransplantation & $>60 \mathrm{yr}$ & 3 \\
\hline & $>25$ points & 0 \\
\hline & No & 2 \\
\hline
\end{tabular}

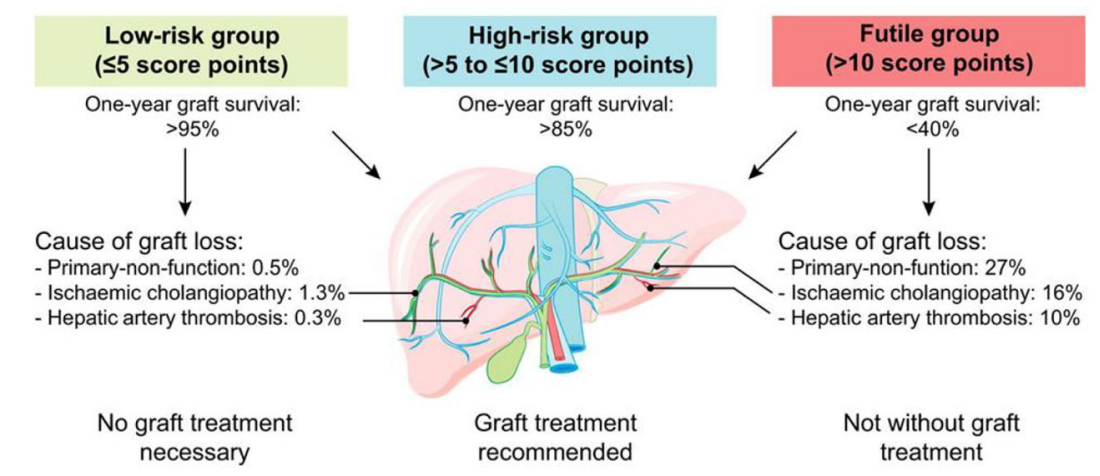

Fig. 4 The UK DCD-Risk Index [35]

these grafts, particularly when the degree of steatosis approaches $30 \%$ or greater.

\section{IC Rates and Risk Tolerance}

Ischemic cholangiopathy (IC) represents the Achilles heel of DCD LT. While severe cases of IC frequently require re-transplantation, ischemic biliary strictures can present with a spectrum of clinical and radiologic severity following LT [56]. Several distinct radiologic patterns of IC have been described, which are associated with different clinical courses [57, 58]:

- Diffuse necrosis

- Bilateral multifocal/multifocal progressive

- Confluence dominant

- Minor Form

Recipients who develop diffuse necrosis rapidly develop abnormalities of nearly the entire biliary system, are identified soon after transplant, and almost uniformly require re-transplantation. Patients with a bilateral multifocal pattern begin with mild to moderate stenosis of the second-order and peripheral ducts and progressively worsen over time. In the confluence dominant pattern, recipients develop strictures confined to the biliary confluence, with relative preservation of the second-order and peripheral ducts. In this pattern, biliary abnormalities progress in severity over time but geographically never expanded beyond the hilar confluence. Many of these patients can be successfully managed long term with ERCP and stenting and frequently do not go on to need re-transplantation. Finally, in the Minor Form, patients may display mild radiologic abnormalities consistent with early IC, but never go on to develop more extensive strictures.

While IC is observed as a complication of both DBD and DCD LT, initial series with DCD LT demonstrated IC rates as high as $30 \%$ with DCD LT compared with rates of $2-4 \%$ seen with DBD LTs [1-5, 7] [1-5, 24]. More recent single-center series from North America providing era stratified data have described IC rates following DCD LT ranging from 2.6 to $5.3 \%$ (Table 4) $[5,7,59,60]$. These data suggest that with strict donor and recipient selection, rates of IC similar to that observed with DBD LT can be achieved. All DCD LT have some inherent risk of IC. This level of risk can be thought of as a "dial" that increases as one accepts riskier donor or recipient variables (Fig. 5). Transplant programs must ask themselves what rate of IC is "acceptable" to them and this will guide which DCD organs they pursue for which recipients. This risk tolerance will influence what any transplant program deems an acceptable DCD donor and an acceptable DCD liver graft recipient. Risk tolerance may vary substantially in different environments based on a multitude of factors. These could include donor availability, waitlist mortality, regulatory environment, cultural expectation, program experience, and ability to re-transplant a patient should significant IC develop. Significant variability in acceptable DCD donor and recipient risk factors may exist between countries or even within a country based on some of the aforementioned factors. In addition, newer technologies such as machine perfusion may allow for modification or at minimum improved prediction of the level of risk associated with each DCD graft.

\section{Machine Perfusion}

During the past decade, there has been renewed interest in the use of machine perfusion instead of static cold storage (SCS)

Table 4 Frequency of IC in DCD recipients in the most recent era

\begin{tabular}{llll}
\hline Center & Era & IC $(\%)$ & DCD $(N=)$ \\
\hline Mayo Clinic Florida [5] & $2010-2015$ & 4 & 100 \\
Oschsner Clinic [7] & $2010-2015$ & 3 & 100 \\
University of Toronto [58] & $2009-2017$ & 2.6 & 77 \\
Indiana University [59] & $2011-2015$ & 5.3 & 38 \\
\hline
\end{tabular}




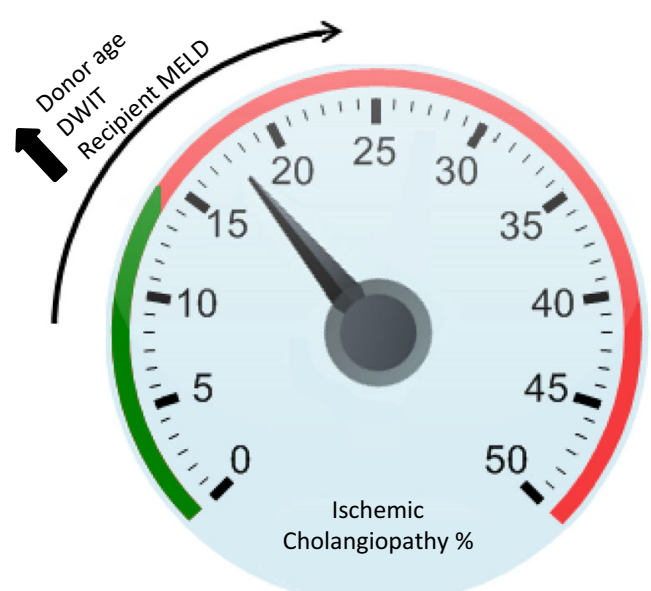

Fig. 5 Dial of ischemic cholangiopathy risk with increasingly riskier DCD liver transplant variables

as a preservation technique for donor livers. Machine perfusion (MP) has several theoretical benefits including organ repair that may lead to improved organ quality, pretransplantation viability assessment of the donor organ, and extending the amount of time between organ recovery and LT. Various strategies for the utilization of MP have been explored with a variety of temperature settings. MP is classified as hypothermic, subnormothermic, and normothermic, with the temperature maintained at $0-12{ }^{\circ} \mathrm{C}, 25-34{ }^{\circ} \mathrm{C}$, and $35-$ $38^{\circ} \mathrm{C}$, respectively [61]. The more commonly described machine perfusion techniques as they relate to DCD LT are described below.

\section{Normothermic Regional Perfusion}

Normothermic regional perfusion (NRP) involves in situ perfusion of the subdiaphragmatic abdominal region after isolation from the remainder of the circulation. This in situ oxygenated perfusion occurs after declaration of circulatory death and prior to organ procurement, with the goal of resuscitating the organs and restoration of intracellular energy stores. NRP relies on cardiopulmonary bypass (CPB)/extracorporeal membrane oxygenator (ECHMO) technology to recover donor venous blood, deliver it to a membrane oxygenator, and then return the oxygenated blood to the subdiaphragmatic aorta. This form of MP has gained significant traction in Europe, where in some countries, such as Italy, the "no touch" time for DCD donors is $20 \mathrm{~min}$ following circulatory arrest. In the USA, NRP technology has been described for DCD donors by the University of Michigan [62]. In their previous publication, they describe their experience with 21 DCD liver procurements of which 13 livers were ultimately transplanted. In that series, 1- and 2-year graft-survival rates were $85.7 \%$ and $71.4 \%$, respectively, while IC and PNF were reported in one patient each. The majority of publications on NRP have originated from European series. A national study from Spain compared $N=95$ liver grafts from controlled DCD (cDCD) donors that underwent NRP with $N=117$ non-NRP cDCD liver grafts [63]. The authors found that NRP was associated with a lower rate of IC ( $2 \%$ for NRP vs. $13 \%$ for non-NRP) and graft loss ( $12 \%$ for NRP vs. $24 \%$ for non-NRP). A study from the UK compared $N=43$ liver grafts from DCD donors that underwent NRP with $N=187$ non-NRP DCD liver grafts [64]. In that study, the use of NRP was associated with a reduction in $\mathrm{EAD}$ ( $12 \%$ for NRP vs. $32 \%$ for non-NRP livers), 30-day graft loss (2\% NRP livers vs. $12 \%$ non-NRP liver), and IC ( $0 \%$ for NRP vs. $27 \%$ for non-NRP livers). A study from Italy investigated outcomes in $N=20 \mathrm{DCD}$ donors that underwent NRP [65]. In Italy, DCD donors experienced a prolonged DWIT as a 20-min no-touch period is required following circulatory arrest. PNF was seen in 2 patients (10\%), IC was seen in 2 patients (10\%), and 1-year graft and patient survival were $85 \%$ and $95 \%$ respectively.

\section{Normothermic EX Vivo Machine Perfusion}

Normothermic MP is designed to maintain full physiological cellular metabolism by perfusing the liver with oxygenated blood-based solutions at body temperature. Normothermic ex vivo machine perfusion (NMP) has the potential to restore normal metabolic physiology, recondition marginal livers, and allow for assessment of graft viability. Functional markers such as bile production and composition, lactate clearance, $\mathrm{pH}$, and transaminases in the perfusate have been suggested as surrogate markers of IRI, liver transplantability, and graft performance after transplantation. Multiple different NMP platforms, at various stages of development, have been described in the literature. While none of these platforms is yet FDA approved, clinical trials have been performed in Europe and are currently underway in the USA. The devices currently used in clinical trials are OrganOx Metra ${ }^{\circledR}$ (OrganOx Ltd., Oxford, UK), Liver Assist ${ }^{\circledR}$ (Organ Assist, Gronigen, the Netherlands), OCS Liver System $®$ (Transmedics, Andover, MA, USA), and the Cleveland NMP circuit (Cleveland Clinic, Cleveland, OH, USA).

Data on the utility of NMP with DCD LT is somewhat limited. A study by Watson et al. used NMP (Liver Assist platform) to assess viability prior to LT [66]. In that study, the authors investigated 47 declined liver grafts (12 DBD, 35 DCD), of which 22 resulted in transplantation. The authors concluded that liver viability during NMP might be assessed using a combination of transaminase release, glucose metabolism, and lactate clearance, and the ability to maintain acidbase balance. A randomized clinical trial using the Organox platform compared $N=121$ grafts from donors that underwent NMP (DBD $N=87$, DCD $N=34$ ) with 101 SCS livers used for LT [67]. In that study, the authors demonstrated a $50 \%$ lower level of hepatocellular enzyme release, a $50 \%$ lower rate of organ discard, and a reduction in post-reperfusion 
syndrome (12.4\% for NMP vs. $33.0 \%$ for SCS) for NMP compared with SCS. No difference in bile duct complications, graft survival, or patient survival was seen between the groups.

\section{Hypothermic Machine Perfusion}

Hypothermic machine perfusion (HMP) is designed to provide perfusion of the liver graft with perfusate temperature most commonly defined as $4{ }^{\circ} \mathrm{C}$. HMP has been well described in kidney transplantation, where large multicenter trials have demonstrated that HMP can improve early graft function and 1-year allograft survival $[68,69]$. The first clinical series of liver hypothermic machine perfusion by Guarrera et al. demonstrated post-LT shortened length of hospital stay, reduced peak serum AST levels, and an improved renal function, despite demonstrating no difference in primary nonfunction (PNF), EAD, graft, and patient survival in a cohort of DBD LTs [70].

Whether HMP alone supplies sufficient oxygenation through oxygen dissolved in the perfusate under atmospheric pressure for a hypothermic liver with its lower metabolic rate has been questioned. In a 2014 study, hypothermic oxygenation machine perfusion (HOPE) was utilized for a cohort of DCD donors [71]. This study demonstrated that the outcome of DCD LT after HOPE conditioning was comparable with matched DBD liver grafts in terms of aspartate aminotransferase/alanine aminotransferase (AST/ALT), intensive care unit admission, and hospital stay. More recently, the concept of DHOPE involving the hypothermic oxygenation through the hepatic artery in addition to the portal vein used in HOPE has been proposed. A recent case control study from the Groningen group in 10 DCD LT patients found a higher graft survival and a lower peak in AST/ALT and bilirubin in DHOPE treated liver grafts [72]. HMP devices currently in development include hypothermic LifePort Liver Transporter machine by Organ Recovery Systems and the VitaSmart hypothermic oxygenated machine perfusion platform by Bridge to Life.

\section{Conclusions}

The landscape of DCD LT is changing on multiple fronts. These changes have been driven by the ongoing organ shortage and continued waitlist mortality in recipients awaiting LT. Encouraging data has suggested that results with DCD LT have improved and that these liver grafts have been increasingly pursued by transplant centers in the modern era. While excellent results can be achieved with DCD LT, it should be stressed that DCD liver grafts should not be thought of as interchangeable with DBD liver grafts, despite highly selected single-center experiences suggesting that in ideal conditions equivalent results can be achieved. To utilize these grafts effectively, numerous aspects of the transplant process from procurement to recipient selection must be carefully controlled and standardized. While liver transplant professionals have made significant progress in the last decade, IC continues to be the Achilles heel of DCD LT. In current practice, no matter how controlled the process or how experienced the transplant program, a certain percentage of patients will inevitably develop IC. When utilizing DCD liver grafts, it is imperative to understand the degree of risk associated with each individual organ offer and recipient situation and to balance this risk with acceptable rates of IC and outcomes based on the environment that transplant program is operating within. This level of risk may vary between countries, transplant centers, and even from recipient to recipient. As future technologies such as MP become increasingly available, the transplant community remains hopeful that the degree of risk associated with DCD LT will be able to be modified in the positive direction allowing for broadening of acceptable DCD donors.

\section{Compliance with Ethical Standards}

Conflict of Interest The authors declare that they have no conflict of interest.

\section{References}

Papers of particular interest, published recently, have been highlighted as:•• Of major importance

1. Foley DP, Fernandez LA, Leverson G, Chin LT, Krieger N, Cooper JT, et al. Donation after cardiac death: the University of Wisconsin experience with liver transplantation. Ann Surg. 2005;242(5):72431.

2. Skaro AI, Jay CL, Baker TB, Wang E, Pasricha S, Lyuksemburg V, et al. The impact of ischemic cholangiopathy in liver transplantation using donors after cardiac death: the untold story. Surgery. 2009;146(4):543-52 discussion 52-3.

3. de Vera ME, Lopez-Solis R, Dvorchik I, Campos S, Morris W, Demetris AJ, et al. Liver transplantation using donation after cardiac death donors: long-term follow-up from a single center. Am J Transplant. 2009;9(4):773-81.

4. Jay C, Ladner D, Wang E, Lyuksemburg V, Kang R, Chang Y, et al. A comprehensive risk assessment of mortality following donation after cardiac death liver transplant - an analysis of the national registry. J Hepatol. 2011;55(4):808-13.

5. Croome KP, Lee DD, Perry DK, Burns JM, Nguyen JH, Keaveny AP, et al. Comparison of longterm outcomes and quality of life in recipients of donation after cardiac death liver grafts with a propensity-matched cohort. Liver Transpl. 2017;23(3):342-51.

6. Laing RW, Scalera I, Isaac J, Mergental H, Mirza DF, Hodson J, et al. Liver transplantation using grafts from donors after circulatory death: a propensity score-matched study from a single center. Am J Transplant. 2016;16(6):1795-804.

7. Bohorquez H, Seal JB, Cohen AJ, Kressel A, Bugeaud E, Bruce DS, et al. Safety and outcomes in 100 consecutive donation after 
circulatory death liver transplants using a protocol that includes thrombolytic therapy. Am J Transplant. 2017 Aug;17(8):2155-64.

8. A definition of irreversible coma. Report of the ad hoc committee of the Harvard medical school to examine the definition of brain death. JAMA. 1968;205(6):337-40.

9. Casavilla A, Ramirez C, Shapiro R, Nghiem D, Miracle K, Bronsther O, et al. Experience with liver and kidney allografts from non-heart-beating donors. Transplantation. 1995;59:197-203.

10. D'Alessandro AM, Hoffmann RM, Knechtle SJ, Eckhoff DE, Love RB, Kalayoglu M, et al. Successful extrarenal transplantation from non-heart-beating donors. Transplantation. 1995;59:977-82.

11.• Croome KP, Lee DD, Keaveny AP, Taner CB. Improving national results in liver transplantation using grafts from donation after cardiac death donors. Transplantation. 2016;100(12):2640-7 This study demonstrates that DCD LT outcomes in the USA have improved in the modern era.

12. New national liver and intestinal organ transplant system in effect Feb. 4, 2020 https://unos.org/policy/liver-distribution/ Accessed February 28, 2020.

13.• Croome KP, Lee DD, Keaveny AP, Taner CB. Noneligible donors as a strategy to decrease the organ shortage. Am J Transplant. 2017;17(6):1649-55. https://doi.org/10.1111/ajt.14163 Epub 2017 Jan 31. This article describes the wide varyance in DCD liver graft utilization and suggests potential reasons for why this variance in seen.

14. Hobeika MJ, Menser T, Nguyen DT, Beal LL, Zajac S, Graviss EA. United States donation after circulatory death liver transplantation is driven by a few high-utilization transplant centers. Am J Transplant. 2020;20(1):320-1.

15. Croome KP, Lee DD, Burns JM, Keaveny AP, Taner CB. Intraregional model for end-stage liver disease score variation in liver transplantation: disparity in our own backyard. Liver Transpl. 2018;24(4):488-96.

16. Montgomery JR, Highet A, Hobeika MJ, Englesbe MJ, McElroy LM. Going the distance for procurement of donation after circulatory death livers for transplantation-Does reimbursement reflect reality? Clin Transpl. 2020 Feb;34(2):e13780.

17. Bernat JL, D'Alessandro AM, Port FK, et al. Report of a national conference on donation after cardiac death. Am J Transplant. 2006;6:281-91.

18. Lewis J, Peltier J, Nelson H, Snyder W, Schneider K, Steinberger $\mathrm{D}$, et al. Development of the University of Wisconsin donation after cardiac death evaluation tool. Prog Transplant. 2003;13:265-73.

19. Rabinstein AA, Yee AH, Mandrekar J, Fugate JE, de Groot YJ, Kompanje EJO, et al. Prediction of potential for organ donation after cardiac death in patients in neurocritical care state: a prospective observational study. Lancet Neurol. 2012;11:414-9.

20. Ishaque $T$, Massie AB, Bowring MG, Haugen CE, Ruck JM, Halpern SE, et al. Liver transplantation and waitlist mortality for HCC and non-HCC candidates following the 2015 HCC exception policy change. Am J Transplant. 2019;19(2):564-72.

21. Schaubel DE, Sima CS, Goodrich NP, Feng S, Merion RM. The survival benefit of deceased donor liver transplantation as a function of candidate disease severity and donor quality. Am J Transplant. 2008;8:419-25.

22. Croome KP, Lee DD, Harnois D, Taner CB. Effects of the share 35 rule on waitlist and liver transplantation outcomes for patients with hepatocellular carcinoma. PLoS One. 2017;12(1):e0170673.

23. Ho KJ, Owens CD, Johnson SR, Khwaja K, Curry MP, Pavlakis M, et al. Donor postextubation hypotension and age correlate with outcome after donation after cardiac death transplantation. Transplantation. 2008;85(11):1588-94.

24. Mateo R, Cho Y, Singh G, Stapfer M, Donovan J, Kahn J, et al. Risk factors for graft survival after liver transplantation from donation after cardiac death donors: an analysis of OPTN/UNOS data. Am J Transplant. 2006;6:791-6.
25. Taner CB, Bulatao IG, Perry DK, Sibulesky L, Willingham DL, Kramer DJ, et al. Asystole to cross- clamp period predicts development of biliary complications in liver transplantation using donation after cardiac death donors. Transpl Int. 2012;25:838-46.

26. Taner CB, Bulatao IG, Willingham DL, Perry DK, Sibulesky L, Pungpapong S, et al. Events in procurement as risk factors for ischemic cholangiopathy in liver transplantation using donation after cardiac death donors. Liver Transpl. 2012;18(1):100-11.

27. Perera MT. The super-rapid technique in Maastricht category III donors: has it developed enough for marginal liver grafts from donors after cardiac death? Curr Opin Organ Transplant. 2012;17(2):131-6.

28. Reich DJ, Mulligan DC, Abt PL, Pruett TL, Abecassis MM, D'Alessandro A, et al. ASTS recommended practice guidelines for controlled donation after cardiac death organ procurement and transplantation. Am J Transplant. 2009 ;9(9):2004-11.

29. Transplantation from deceased donors after circulatory death: British Transplant Society Guidelines. https://bts.org.uk/wpcontent/uploads/2016/09/15_BTS_Donors_DCD-1.pdf Accessed Feb 102020.

30. Eurotransplant. Eurotransplant manual - Chapter 9 The Donor. 2016.

31. Abradelo de Usera M, Blasi Ibáñez A, Fundora Suárez Y, Fondevila Campo C, Gómez Gutiérrez M, Sánchez Turrión V. Protocolo nacional de donación y trasplante hepático en donación en asistolía controlada. 2015.

32. Farid SG, Attia MS, Vijayanand D, Upasani V, Barlow AD, Willis $\mathrm{S}$, et al. Impact of donor hepatectomy time during organ procurement in donation after circulatory death liver transplantation: the United Kingdom experience. Transplantation. 2019;103(4):e7988.

33. Khorsandi S, et al. Developing a donation after cardiac death risk index for adult and pediatric liver transplantation. World J Transplant. 2017;7(3):203-12.

34. van Leeuwen O, van Reeven M, Fujiyoshi M, de Meijer VE, de Kleine R, de Boer M, et al. American Journal of Transplantation, vol. $18 ; 2018$. p. 572-573 2.

35. Mathur AK, Heimbach J, Steffick DE, Sonnenday CJ, Goodrich NP, Merion RM. Donation after cardiac death liver transplantation: predictors of outcome. Am J Transplant. 2010;10(11):2512-9.

36.• Schlegel A, Kalisvaart M, Scalera I, Laing RW, Mergental H, Mirza DF, et al. The UK DCD risk score: a new proposal to define futility in donation-after-circulatory-death liver transplantation. J Hepatol. 2018;68(3):456-64 Improvement in DCD LT outcomes has been driven at least partially by better understanding of the importance of donor and recipient matching as described in this study.

37. Sharma H, Bohorquez H, Bruce D, Seal J, Cohen A, Bugeaud E, et al. Pre liver transplant (LT) prediction of surgical complexity by recipient risk grading and optimizing outcomes: the Ochsner experience. Am J Transplant. 2018;18(S4):848-9.

38. Olthoff KM, Kulik L, Samstein B, Kaminski M, Abecassis M, Emond J, et al. Validation of a current definition of early allograft dysfunction in liver transplant recipients and analysis of risk factors. Liver Transpl. 2010;16:943-9.

39. Croome KP, Lee DD, Croome S, Chadha R, Livingston D, Abader $\mathrm{P}$, et al. The impact of postreperfusion syndrome during liver transplantation using livers with significant macrosteatosis. Am J Transplant. 2019;19(9):2550-9.

40. Chadha RM, Croome KP, Aniskevich S, Pai SL, Nguyen J, Burns J, et al. Intraoperative events in liver transplantation using donation after cardiac death donors. Liver Transpl. 2019;25(12):1833-40.

41. Lee DD, Singh A, Burns JM, Perry DK, Nguyen JH, Taner CB. Early allograft dysfunction in liver transplantation with donation after cardiac death donors results in inferior survival. Liver Transpl. 2014;20(12):1447-53. 
42. Wadei HM, Bulatao IG, Gonwa TA, Mai ML, Prendergast M, Keaveny AP, et al. Inferior long-term outcomes of liver-kidney transplantation using donation after cardiac death donors: singlecenter and organ procurement and transplantation network analyses. Liver Transpl. 2014;20(6):728-35.

43. Alhamad T, Spatz C, Uemura T, Lehman E, Farooq U. The outcomes of simultaneous liver and kidney transplantation using donation after cardiac death organs. Transplantation. 2014;98(11): 1190-8.

44. LaMattina JC, Mezrich JD, Fernandez LA, D'Alessandro AM, Bellingham JM, Musat AI, et al. Simultaneous liver and kidney transplantation using donation after cardiac death donors: a brief report. Liver Transpl. 2011;17(5):591-5.

45. Croome KP, Mao S, Yang L, Pungpapong S, Wadei HM, Taner CB. Improved national results with simultaneous liver-kidney transplantation using donation after circulatory death donors. Liver Transpl. 2020;26(3):397-407.

46. Croome KP, Wall W, Chandok N, Beck G, Marotta P, HernandezAlejandro R. Inferior survival in liver transplant recipients with hepatocellular carcinoma receiving donation after cardiac death liver allografts. Liver Transpl. 2013;19(11):1214-23.

47. van der Bilt JD, Kranenburg O, Nijkamp MW, Smakman N, Veenendaal LM, Te Velde EA, et al. Ischemia/reperfusion accelerates the outgrowth of hepatic micrometastases in a highly standardized murine model. Hepatology. 2005;42:165-75.

48. Doi K, Horiuchi T, Uchinami M, Tabo T, Kimura N, Yokomachi J, et al. Hepatic ischemia-reperfusion promotes liver metastasis of colon cancer. J Surg Res. 2002;105:243-7.

49. Croome KP, Lee DD, Burns JM, Musto K, Paz D, Nguyen JH, et al. The use of donation after cardiac death allografts does not increase recurrence of hepatocellular carcinoma. Am J Transplant. 2015;15(10):2704-11.

50. Hong JC, Yersiz H, Kositamongkol P, Xia VW, Kaldas FM, Petrowsky $\mathrm{H}$, et al. Liver transplantation using organ donation after cardiac death: a clinical predictive index for graft failure-free survival. Arch Surg. 2011;146:1017-23.

51. Khorsandi S, Giorgakis E, Vilca-Melendez H, O'Grady J, Heneghan M, Aluvihare V, et al. Developing a donation after cardiac death risk index for adult and pediatric liver transplantation. World J Transplant. 2017;7:203-12.

52. Schlegel A, Scalera I, Thamara M, Perera PR, Kalisvaart M, Mergental H, et al. Impact of donor age in donation after cardiac death liver transplantation: is the cut-off " 60 " still of relevance? Liver Transpl. 2018;24(3):352-62.

53. Croome KP, Mathur AK, Lee DD, Moss AA, Rosen CB, Heimbach $\mathrm{JK}$, et al. Outcomes of donation after circulatory death liver grafts from donors 50 years or older: a multicenter analysis. Transplantation. 2018;102(7):1108-14.

54. Croome KP, Lee DD, Taner CB. The "skinny" on assessment and utilization of steatotic liver grafts: a systematic review. Liver Transpl. 2019;25(3):488-99.

55. Croome KP, Mathur AK, Mao S, Aqel B, Piatt J. Abade Sedki Senada P, Heimbach JK, Moss A, Rosen CB, Taner CB. Perioperative and longterm outcomes of utilizing donation after circulatory death liver grafts with macrosteatosis: a multicenter analysis. Am J Transplant. 2020; \{In-Press $\}$. https://doi.org/10.1111/ajt. 15877.

56. Croome KP, Lee DD, Nguyen JH, Keaveny AP, Taner CB. Waitlist outcomes for patients relisted following failed donation after cardiac death liver transplant: implications for awarding model for endstage liver disease exception scores. Am J Transplant. 2017;17(9): 2420-7.

57. Giesbrandt KJ, Bulatao IG, Keaveny AP, Nguyen JH, PazFumagalli R, Taner CB. Radiologic characterization of ischemic cholangiopathy in donation-after-cardiac-death liver transplants and correlation with clinical outcomes. AJR Am J Roentgenol. 2015;205(5):976-84.

58. Lee HW, Suh KS, Shin WY, Cho EH, Yi NJ, Lee JM, et al. Classification and prognosis of intrahepatic biliary stricture after liver transplantation. Liver Transpl. 2007;13(12):1736-42.

59. Kollmann D, Sapisochin G, Goldaracena N, Hansen BE, Rajakumar R, Selzner N, et al. Expanding the donor pool: donation after circulatory death and living liver donation do not compromise the results of liver transplantation. Liver Transpl. 2018;24(6):77989.

60. Mihaylov P, Mangus R, Ekser B, Cabrales A, Timsina L, Fridell J, et al. Expanding the donor pool with the use of extended criteria donation after circulatory death livers. Liver Transpl. 2019;25(8): 1198-208.

61. Karangwa SA, Dutkowski P, Fontes P, Friend PJ, Guarrera JV, Markmann JF, et al. Machine perfusion of donor livers for transplantation: a proposal for standardized nomenclature and reporting guidelines. Am J Transplant. 2016;16(10):2932-42.

62. Rojas-Peña A, Sall LE, Gravel MT, Cooley EG, Pelletier SJ, Bartlett RH, et al. Donation after circulatory determination of death: the university of Michigan experience with extracorporeal support. Transplantation. 2014;98(3):328-34.

63. Hessheimer AJ, Coll E, Torres F, Ruiz P, Gastaca M, Rivas JI, et al. Normothermic regional perfusion vs. super-rapid recovery in controlled donation after circulatory death liver transplantation. J Hepatol. 2019;70(4):658-65.

64. Watson CJE, Hunt F, Messer S, Currie I, Large S, Sutherland A, et al. In situ normothermic perfusion of livers in controlled circulatory death donation may prevent ischemic cholangiopathy and improve graft survival. Am J Transplant. 2019;19(6):1745-58. https:// doi.org/10.1111/ajt.15241.

65. De Carlis R, Di Sandro S, Lauterio A, Botta F, Ferla F, Andorno E, et al. Liver grafts from donors after circulatory death on regional perfusion with extended warm ischemia compared with donors after brain death. Liver Transpl. 2018;24(11):1523-35.

66. Watson CJE, Kosmoliaptsis V, Pley C, Randle L, Fear C, Crick K, et al. Observations on the ex situ perfusion of livers for transplantation. Am J Transplant. 2018;18(8):2005-20.

67. Nasralla D, Coussios CC, Mergental H, Akhtar MZ, Butler AJ, Ceresa CDL, et al. Consortium for Organ Preservation in Europe. A randomized trial of normothermic preservation in liver transplantation. Nature. 2018;557(7703):50-6.

68. Moers C, Smits JM, Maathuis MH, et al. Machine perfusion or cold storage in deceased-donor kidney transplantation. N Engl J Med. 2009;360(1):7-19.

69. Matsuoka L, Shah T, Aswad S, Bunnapradist S, Cho Y, Mendez $\mathrm{RG}$, et al. Pulsatile perfusion reduces the incidence of delayed graft function in expanded criteria donor kidney transplantation. Am J Transpl. 2006;6(6):1473-8.

70. Guarrera JV, Henry SD, Samstein B, Odeh-Ramadan R, Kinkhabwala M, Goldstein MJ, et al. Hypothermic machine preservation in human liver transplantation: the first clinical series. Am J Transplant. 2010;10(2):372-81.

71. Dutkowski P, Schlegel A, de Oliveira M, Müllhaupt B, Neff F, Clavien PA. HOPE for human liver grafts obtained from donors after cardiac death. J Hepatol. 2014;60(4):765-72.

72. van Rijn R, Karimian N, Matton APM, Burlage LC, Westerkamp $A C$, van den Berg AP, et al. Dual hypothermic oxygenated machine perfusion in liver transplants donated after circulatory death. Br J Surg. 2017;104:907-17.

Publisher's Note Springer Nature remains neutral with regard to jurisdictional claims in published maps and institutional affiliations. 